\title{
Pemuliaan Mutasi Tanaman Nanas (Ananas comosus (L.) Merr.) Menggunakan Iradiasi Gamma untuk Perbaikan Varietas Nanas Smooth Cayenne
}

\section{Plant Mutation Breeding of Pineapple (Ananas comosus (L.) Merr.) Using Gamma Irradiation for Improvement of Smooth Cayenne Variety}

\author{
Soeranto Human ${ }^{1}$, S. Loekito ${ }^{2}$, M. Trilaksono ${ }^{2}$ dan A. Syaifudin ${ }^{2}$ \\ ${ }^{1}$ Pusat Aplikasi Isotop dan Radiasi, BATAN \\ Jl. Lebak Bulus Raya No. 49 Jakarta 12440 \\ ${ }^{2}$ PT. Great Giant Pineapple Company (GGPC) \\ Terbanggi Besar Km. 77, Lampung Tengah, Indonesia \\ Email : soeranto@batan.go.id
}

Diterima 07-12-2015; Diterima dengan revisi 21-12-2015; Disetujui 24-03-2016

\begin{abstract}
ABSTRAK
Pemuliaan Mutasi Tanaman Nanas (Ananas comosus (L.) Merr.) Menggunakan Iradiasi Gamma untuk Perbaikan Varietas Smooth Cayenne. Pada saat ini, jenis nanas yang paling banyak dibudidayakan dalam berbagai perdagangan dunia adalah jenis Smooth Cayenne. Banyak klon yang berasal dari kultivar ini seperti GP1, GP2, GP3, GP4, GP5, dan F180 ditanam oleh GGP baik untuk buahsegar dan olahan. GGPC mulai melakukan usaha perbaikan varietas nanas sejak tahun 1986, yaitu dengan tujuan meningkatkan kualitas dan produksi yang tinggi. Pemuliaan mutasi nanas dimulai pada tahun 2006, yaitu melalui kerjasama dengan Pusat Aplikasi Isotop dan Radiasi (PAIR), Badan Tenaga Nuklir Nasional (BATAN). Sejumlah 10 mahkota (crown) nanas berasal dari GP2, GP3 (A10) dan klon F180 diiradiasi sinar gamma bersumber Cobalt-60 terpasang pada iradiator gamma chamber 4000A dengan dosis 200 dan 300 Gy. Crown yang telah diradiasi kemudian ditanam di lahan percobaan dengan mengikuti budidaya standar komersial di PT. GGPC. Secara umum hasil penelitian menunjukkan tidak ada perbedaan yang signifikan antara kedua dosis iradiasi (200 dan $300 \mathrm{~Gy}$ ) pada fenotipe tanaman. Namun, keragaman fenotipe yang sangat tinggi dijumpai pada klon turunan tanaman vegetatif (V1). Beberapa variasi tanaman yang muncul tercatat sebagai berikut: $47 \%$ tanaman normal, $15 \%$ Rosset, $11 \%$ berduri, $5 \%$ crown bercabang, $4 \%$ tanaman memiliki banyak daun dan $18 \%$ buah berbentuk abnormal. Variasi mutan yang signifikan juga diamati pada klon-lon turunan tanaman V2 dan beberapa mutan tampak lebih stabil pada generasi V3. Program pemuliaan nanas ini akan terus dilanjutkan untuk evaluasi yang berkaitan dengan perbaikan produktivitas, kualitas, dan ketahanan terhadap hama dan penyakit tertentu.
\end{abstract}

Kata Kunci : iradiasi gamma, keragaman mutan, roset, mahkota bercabang.

\begin{abstract}
Plant Mutation Breeding of Pineapple (Ananas comosus (L.) Merr.) Using Gamma Irradiation for Improvement of Smooth Cayenne Variety. Currently, the most famous pineapple cultivar cultivated for the world trade is Smooth Cayenne. Many clones derived from this cultivar such as GP1, GP2, GP3, GP4, GP5, and F180 are grown by GGPC for fresh and processed fruits. GGPC started pineapple breeding and varietal improvement programs in 1986 with the objectives to increase quality, tonage and yield. Mutation breeding in pineapple was started in 2006 i.e. in collaboration with the Center for Isotopes and Radiation Application (CIRA), the National Nuclear Energy Agency (BATAN). A number of 10 pineapple crowns originated from GP2, GP3 (A10) and F180 clones were treated with gamma irradiation from Cobalt-60 source installed in gamma chamber $4000 \mathrm{~A}$, using the doses of 200
\end{abstract}


and 300 Gy. The irradiated crowns were then planted in the experimental field (as V1) and maintained following the GGPC commercial standard cultivation for pineapple. The results showed there was no significant diffrences between the two gamma irradiation doses $(200$ and $300 \mathrm{Gyl}$ on pineapple phenotypic performances. However, high phenotypic variability was found in clones at the second vegetative propagation (V2). Some plant variations were recorded as follows: $47 \%$ of normal vigour, $15 \%$ of rosset, $11 \%$ of spiny, $5 \%$ of crowns with double tips, $4 \%$ of plant having plenty of leaves and $18 \%$ of fruits with abnormal shape. Significant mutant variation was also observed in clones the third vegetative propagation (V3) but some mutants seemed to be more stable in the V3 generation. This pineapple mutation breeding program will be continued for mutant evaluation that is related to improvement of productivity, quality and resistance to major insect and diseases.

Key words : gamma irradiation, mutant variation, rosset, branching crown.

\section{PENDAHULUAN}

Nanas (Ananas comosus L. Merr) merupakan komoditas buah penting bagi Indonesia, baik untuk memenuhi kebutuhan dalam negeri maupun ekspor. Upaya peningkatan produktivitas dan kualitas nanas terus dilakukan melalui program pemuliaan tanaman. Salah satu upaya pemuliaan tanaman nanas dilakukan melalui pemuliaan mutasi yaitu dengan tujuan memperbaiki varietas Smooth Cayenne agar berdaya hasil tinggi, berkualitas baik dan tahan terhadap hama dan penyakit utama. GGPC memulai pemuliaan tanaman nanas sejak tahun 1986, dengan tujuan untuk menghasilkan tanaman dengan produktivitas tinggi dan kualitas yang baik. Sebelumnya, usaha pemuliaan tanaman yang telah dilakukan adalah dengan cara seleksi massa dan karakterisasi beberapa aksesi nanas yang sudah ada [1].

Sebetulnya perbaikan varietas nanas dapat dilakukan dengan metode pemuliaan tanaman pada umumnya seperti introduksi, seleksi, hibridisasi, mutasi dan bioteknologi. Namun, kegagalan dalam proses pemuliaan tanaman secara hibridisasi sering dikarenakan oleh tingkat heterezigotas tanaman yang tinggi dan juga adanya selfincincompatibility pada bunga [2]. Upaya untuk mengatasi masalah selfincompatibility pada bunga nanas telah dilakukan dengan menggunakan teknik pemuliaan mutasi (mutation breeding) dan beberapa mutan tanaman nanas telah dihasilkan [3].
Pemuliaan mutasi telah umum digunakan dalam rekayasa keragaman genetik tanaman [4, 5]. Mutasi induksi sangat membantu dalam upaya peningkatan keragaman genetik tanaman yang dijumpai masih terbatas [6, 7]. Induksi mutasi dapat dilakukan baik dengan mutagen fisika seperti sinar gamma maupun dengan mutagen kimia seperti Ethyl Methan Sulfonate [8, 9]. Di Indonesia pemuliaan mutasi tanaman telah menghasilkan banyak varietas unggul tanaman termasuk padi, kedelai, kacang hijau, kapas, sorgum dan gandum tropis [10].

Tanaman nanas sulit untuk menghasilkan bunga karena memerlukan waktu lama, sehingga hibridisasi sulit pula dilakukan. Perbanyakan tanaman nanas pada umumnya melalui cara vegetatif (vegetatively propagated) yaitu melalui mahkota buah nanas (crown). Oleh karena itu cara yang paling efisien untuk meningkatkan keragaman genetik adalah melalui mutasi induksi (induced mutation), seperti yang telah dilakukan pada tanaman pisang [11]. Keragaman genetik tanaman yang tinggi diperlukan sebagai dasar populasi (base population) untuk proses seleksi tanaman dengan genotype unggul dalam program pemuliaan tanaman [12].

\section{BAHAN DAN METODE}

Penelitian ini dilakukan secara bersama antara peneliti di Pusat Aplikasi Isotop dan Radiasi (PAIR) - Badan Tenaga 
Nuklir Nasional (BATAN) di Jakarta dan PT. Great Giant Pineapple Company (GGPC) di Lampung. Iradiasi gamma pada materi tanaman nanas dilakukan di PAIR-BATAN, sedangkan penelitian lapangan dilakukan dilahan percobaan milik PT. GGPC di Terbanggi Besar, Lampung Tengah pada bulan Juni 2006 - September 2013.

Secara biologi nanas tergolong tanaman berpenyerbuk sendiri (selfpollinated) namun persentasi penyerbukan silang (cross-pollination) terjadi cukup tinggi [13]. Atas dasar sistem penyerbukan tersebut, maka perbanyakan secara vegetatif menggunakan mahkota buah (crown) lebih banyak diaplikasikan pada pemuliaan tanaman nanas. Dalam penelitian ini, plantlet tanaman yang digunakan terdiri dari mahkota buah dari 3 klon varietas nanas Smooth Cayenne yaitu GP2, GP3 (A10) dan F180. Alat utama yang digunakan adalah iradiator gamma chamber $4000 \mathrm{~A}$ yang memancarkan sinar gamma dari sumber Cobalt-60 yang terpasang di dalamnya. Iradiator gamma ini yang digunakan dalam menginduksi mutasi tanaman nanas.

Masing-masing sebanyak 10 mahkota buah nanas berasal dari klon induk GP2, GP3 (A10) dan klon F180 diiradiasi dengan sinar gamma dosis 200 dan 300 Gy. Mahkota buah yang telah diiradiasi kemudian ditanam di lahan percobaan dengan mengikuti teknik budidaya standar komersial di PT. GGPC (sebagai populasi vegetatif V1). Tanaman V1 kemudian dikultur jaringan di media tumbuh MS yang telah dimodifikasi dengan hormon, diregenerasi dan ditanam kembali di lapangan sebagai populasi vegetatif V2. Pengamatan dan seleksi mutan mulai dilakukan pada V2 berdasarkan perubahan penampilan fenotip yang secara visual berbeda nyata dari klon induk. Tanaman terseleksi kemudian disub-kultur, diregenerasi dan ditanam kembali di lapangan sebagai populasi vegetatif V3.

Evaluasi mutan dilakukan pada populasi vegetatif V3 yaitu meliputi kestabilan performa beberapa sifat agronomi penting seperti bentuk dan struktur tanaman, warna daun serta perubahan ukuran dan warna buah. Klon mutan terpilih kemudian dipelajari stabilitas genotipnya pada populasi vegetatif V4 berdasarkan data hasil uji observasi menggunakan metoda AMMI Biplot seperti yang telah diaplikasikan pada tanaman sorgum [14].

\section{HASIL DAN PEMBAHASAN}

Secara keseluruhan respon setiap individu tanaman berbeda terhadap perlakuan iradiasi gamma dosis 200 Gy dan $300 \mathrm{~Gy}$, tetapi intensitas perubahan tidak berbeda secara signifikan pada level tanaman pada generasi V1. Observasi pada V2 menunjukkan bahwa klon induk tanaman memberikan respon yang berbeda terhadap iradiasi gamma, dan perubahan yang sangat nyata terlihat pada munculnya keragaman bentuk, ukuran dan warna buah. Penampilan visual perubahan buah dari setiap klon induk disajikan dalam Gambar 1 dan Gambar 2.

Buah dari tanaman hasil iradiasi gamma dengan doss $200 \mathrm{~Gy}$ dan $300 \mathrm{~Gy}$ pada umumnya memiliki mata yang menonjol bila dibandingkan dengan tanaman yang tidak diiradiasi (kontrol). Secara deskriptif buah dari klon induk F180 dan A10 adalah berbentuk agak kerucut, namun setelah perlakuan iradiasi gamma dosis 200 Gy dan 300 Gy, bentuk buah berubah menjadi relatif silindris dengan ukuran panjang buah berkisar antara $15-18$ $\mathrm{Cm}$. Perubahan yang terjadi pada buah dari klon induk GP2, iradiasi gamma dosis 200 Gy dan 300 Gy memberikan pengaruh nyata pada susunan mahkota (crown). Pada awalnya mahkota buah tanaman yang tidak diiradiasi (kontrol) tersusun beraturan, namun iradiasi gamma memberikan perubahan sususan mahkota menjadi acak dan tidak beraturan serta mata buah berubah menjadi menonjol. Pengkajian lebih lanjut kini sedang dilakukan untuk mengetahui apakah perubahan pada mahkota buah dan mata buah yang 


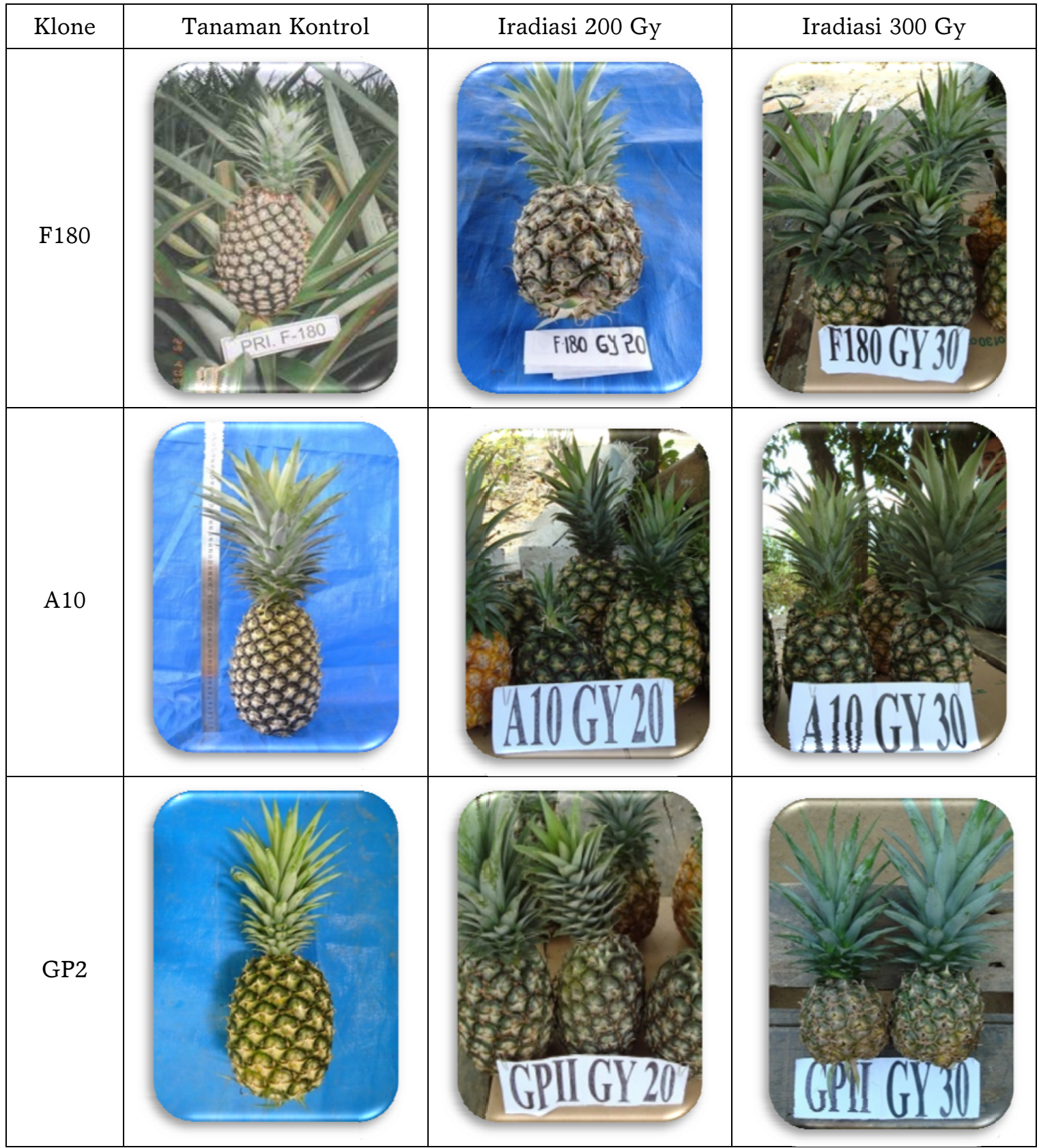

Gambar 1. Pengaruh iradiasi gamma pada keragaman buah nanas yang teramati pada generasi vegetatif V2.

menonjol tersebut berkorelasi positif terhadap produktivitas dan kualitas buah nanas.

Iradiasi gamma dosis 200 dan $300 \mathrm{~Gy}$ memberikan efek sangat signifikan terhadap bentuk, ukuran, warna dan kualitas buah nanas (Gambar 2). Pada umumnya penampang buah klon induk yang diiradiasi berubah menjadi mengecil dan memiliki buah translusen (lebih lembek) dengan diameter core (tulang buah) lebih besar dibanding dengan buah tanaman klon tidak disinari (tanaman control). Pembesaran diameter core disebabkan oleh $P$-duncle juga lebih membesar. Tercatat rerata diameter core buah berubah antara $3,2-3,8 \mathrm{~cm}$. Seperti terlihat pada Gambar 2, warna daging buah nanas juga berubah sebagai 
pengaruh dari iradiasi gamma. Perubahan dari warna putih ke kuning bervariasi tergantung pada klon induk dan dosis iradiasi yang diberikan.

Iradiasi gamma diduga merubah kandungan gula di dalam buah nanas. Untuk daging buah yang berubah menjadi kuning, dipastikan memiliki kandungan gula yang lebih tinggi karena rasanya lebih manis dibanding buah bewarna putih. Kandungan gula di dalam buah sangat menentukan kualitas nanas. Buah nanas dengan kandungan gula tinggi dan berasa manis biasanya lebih diperuntukan sebagai buah segar (fresh fruit). Sedangkan buah yang tidak manis pada umumnya lebih diperuntukkan untuk diproses menjadi buah kaleng (canned fruit).

Pengaruh iradiasi gamma teramati tidak hanya pada buah tapi juga pada struktur dan warna daun tanaman maupun daun mahkota. Beberapa pengamatan menunjukkan bahwa iradiasi gamma dosis 200 dan 300 Gy memberikan perubahan drastis pada daun dan mahkota buah. Pada beberapa kasus daun berubah menjadi berduri, ukuran daun menjadi mengecil dan terbelah serta mahkota buah menjadi bercabang. Ada pula perubahan jumlah daun menjadi lebih banyak dengan warna daun menjadi roset (pink kemerahan). Perubahan drastis semacam itu mungkin memberikan nilai positif apabila nanas diperuntukkan sebagai tanaman hias yang menghendaki sifat dekoratif atau artistik (Gambar 3).

Grafik persentasi mutan nanas yang dihasilkan dari iradiasi gamma disajikan dalam Gambar 4. Pada populasi vegetatif V2 terlihat bahwa persentasi mutan teramati sebagai berikut: $11 \%$ mahkota (crown) bercabang, $11 \%$ daun berduri, $9 \%$ daun roset, $47 \%$ tanaman normal, $5 \%$ berdaun kecil dan banyak, 25\% buah abnormal. Pada

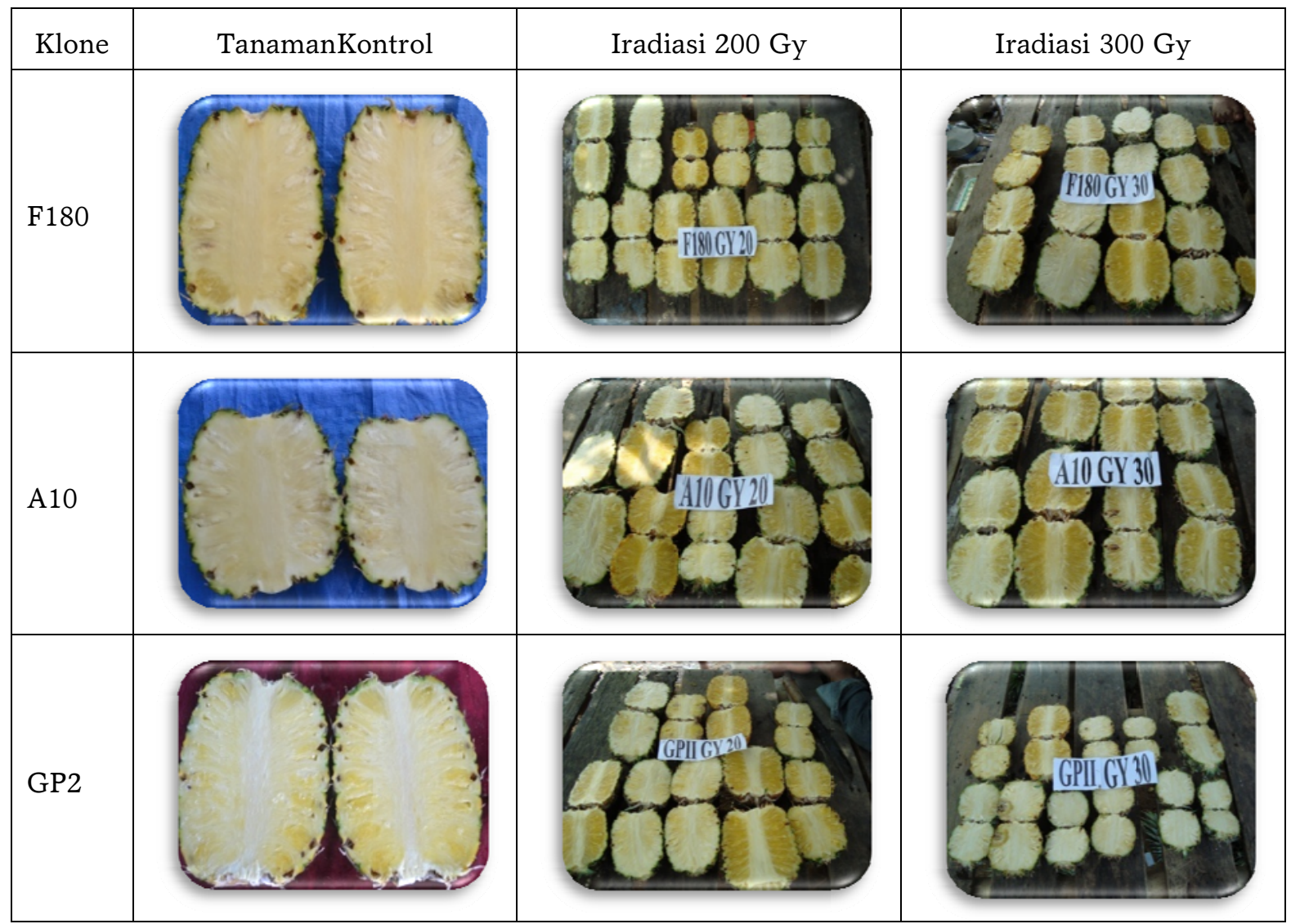

Gambar 2. Pengaruh iradiasi gamma pada perubahan bentuk, ukuran dan warna buah nanas pada generasi vegetatif $\mathrm{V} 2$. 
populasi vegetatif V3 persentasi mutan tercatat sebagai berikut: $5 \%$ crown bercabang, $11 \%$ daun berduri, $15 \%$ daun roset, $47 \%$ tanaman normal, $4 \%$ berdaun kecil dan banyak, $18 \%$ buah abnormal.

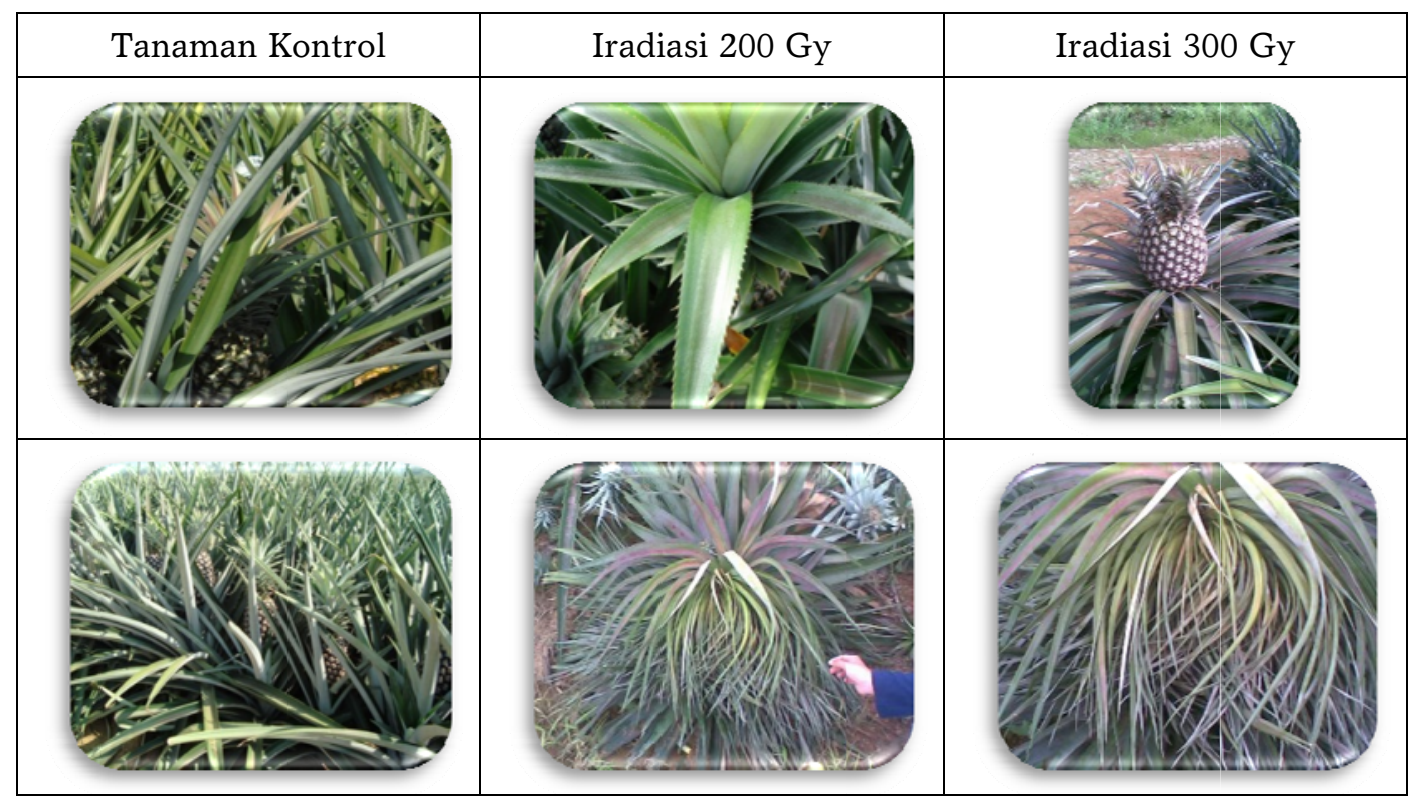

Gambar 3. Pengaruh iradiasi gamma pada keragaman daun tanaman nanas.

Persen Potensi Mutan Respon dari Penyinaran Gamma 20 dan 30 KGy (M1)

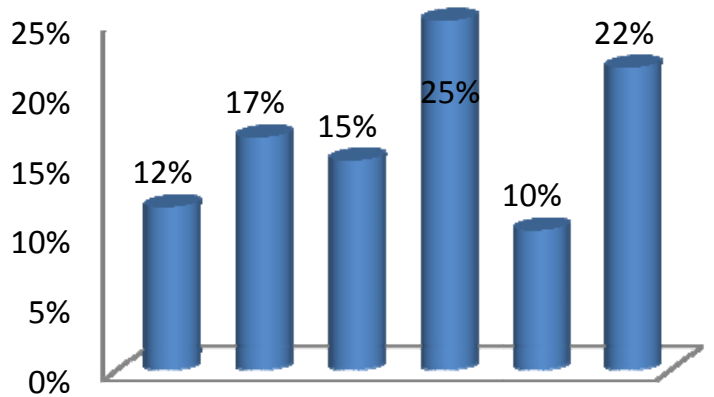

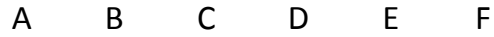

Persen Potensi Mutan Respon dari Iradiasi Gamma 200 dan 300 Gy (V3)

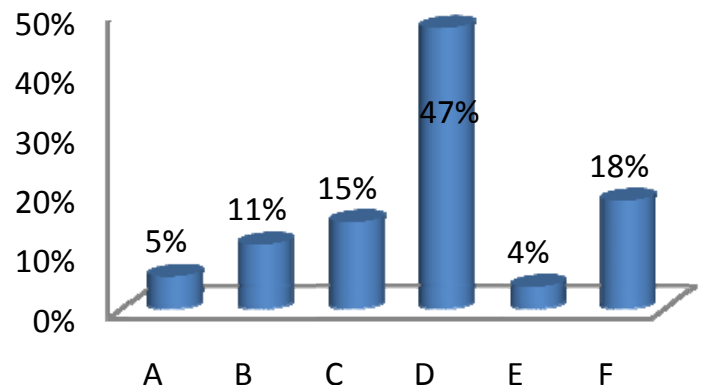

Persen Potensi Mutan Respon dari Iradiasi Gamma 200 dan 300 Gy (V2)

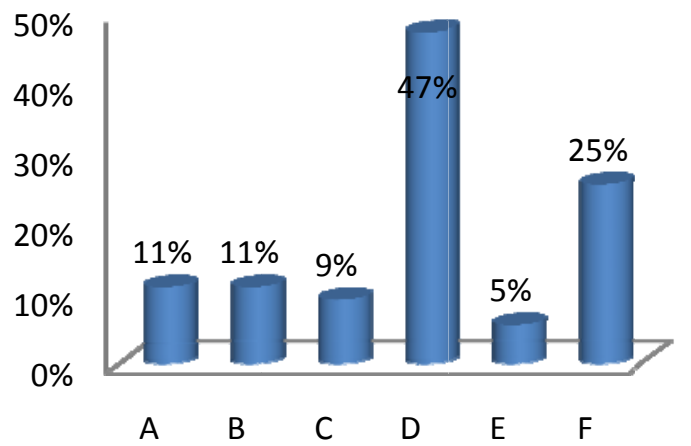

A : Crown Cabang

B : Berduri

C : Roset

D : Tanaman Normal

E : Berdaun Banyak

F : Buah Abnormal

Gambar 4. Grafik persentase mutan nanas yang dihasilkan dari iradiasi gamma. 
Jumlah mutan tanaman yang dihasilkan dari perlakuan iradiasi gamma dosis 200 dan 300 Gy pada populasi vegetatif V3 diringkas dalam Tabel 1. Keragaman sifat pada V2 tampak diturunkan pada generasi V3 dan memiliki ferforma yang berbeda nyata mutan yang satu dan mutan lainnya, khususnya bila efektivitas proses seleksi tanaman oleh pemulia tanaman bersangkutan. Pada akhirnya terhadap klon-klon nanas unggul yang telah dihasilkan tersebut, maka perlu dikaji interaksinya dan stabilitas genetiknya pada berbagai lingkungan tumbuh yaitu sebagai salah satu persyaratan dalam program pemuliaan tanaman [16]. Analisis

Tabel 1. Jumlah mutan tanaman pada populasi vegetatif V3.

\begin{tabular}{ccc}
\hline Klon Induk & Dosis Iradiasi Gamma & Jumlah Mutan Dihasilkan \\
\hline A10 & $200 \mathrm{~Gy}$ & 3 \\
A10 & $300 \mathrm{~Gy}$ & 8 \\
F180 & $200 \mathrm{~Gy}$ & 8 \\
F180 & $300 \mathrm{~Gy}$ & 10 \\
GP2 & $200 \mathrm{~Gy}$ & 10 \\
GP2 & $300 \mathrm{~Gy}$ & 16 \\
\hline \multicolumn{2}{c}{} \\
\hline
\end{tabular}

dibandingkan dengan klone induknya. Penurunan sifat dari V2 ke V3 menandakan adanya perubahan genetik di dalam tanaman. Program pemuliaan nanas ini akan terus dilanjutkan untuk evaluasi sifat-sifat tanaman yang berkaitan dengan perbaikan produktivitas, kualitas, dan ketahanan terhadap hama dan penyakit tertentu.

Penelitian ini telah menghasilkan sebanyak 55 mutan tanaman nanas pada populasi vegetatif V3. Mutan-mutan tersebut perlu diteliti dan diuji lebih lanjut agar dapat dilepas menjadi klon atau varietas unggul baru, atau mungkin digunakan dalam program hibridisasi. Alhasil, penelitian ini telah membuktikan bahwa iradiasi gamma dapat meningkatkan ragam genetik tanaman dan akan berguna dalam program pemuliaan tanaman nanas lebih lanjut. Hasil penelitian ini sejalan dengan beberapa pendapat yang menyatakan bahwa pada dosis tertentu, iradiasi gamma beguna dalam mengubah genetik dan fenotif tanaman [15]. Selanjutnya, perubahan positif yang diinginkan tentu tergantung pada tujuan dan produktivitas dan kualitas buah nanas perlu juga dilakukan melalui uji observasi di berbagai lokasi percobaan sebelum akhirnya diusulkan untuk dilepas menjadi varietas/ klon unggul nanas baru.

\section{KESIMPULAN}

Respon tanaman nanas terhadap iradiasi gamma bervariasi tergantung pada klon induk dan dosis iradiasi gamma yang digunakan.

Iradiasi gamma telah menimbulkan keragaman fenotip pada generasi V2 yang kemudian diturunkan pada V3. Penurunan sifat dari V2 ke V3 menandakan adanya perubahan genetik di dalam tanaman. Sebanyak 55 mutan tanaman nanas dihasilkan pada populasi vegetatif V3. Keragaman mutan tanaman tersebut akan berguna dalam program pemuliaan tanaman nanas selanjutnya.

Spektrum mutasi pada tanaman nanas yang dihasilkan bervariasi yaitu meliputi 
mahkota (crown) bercabang, daun berduri, warna daun roset, jumlah daun lebih banyak, serta adanya perubahan bentuk, ukuran dan warna buah nanas.

\section{UCAPAN TERIMAKASIH}

Penulis mengucapkan terimakasih kepada Pusat Aplikasi Isotop dan Radiasi (PAIR), Badan Tenaga Nuklir Nasional (BATAN) atas bantuan fasilitas iradiator gamma untuk penelitian ini. Terimakasih juga disampaikan kepada PT. Great Giant Pineapple Company (GGPC) di Lampung yang telah memberikan bahan penelitian tanaman nanas serta menyediakan fasilitas percobaan laboratorium kultur jaringan dan lapangan.

\section{DAFTAR PUSTAKA}

1. ZHYKRI F., MISWAR., SUKARMIN. dan F. IHSAN, Tehnik Karakterisasi Kuantitatif beberapa Aksesi Nanas, Buletin Teknik Pertanian, 17 (1), 1013 (2012).

2. RICHARDS, A.J., Plant Breeding System, Second Edition, Chapman \& Hall. ISBN 0-412-57440-3 (1997).

3. BROETJES, C. and VAN HARTEN, A.M., Application of mutation breeding methods in the improvement of vegetatively propagated crops, Elsevier Publ. ISBN 0-444-41618-8 (1998).

4. VAN HARTEN, A.M., Mutation Breeding Theory and Practical Applications, Cambridge, ISBN 0521-47074-9 (1998).

5. SHU, Q.Y., FOSTER, B.P., NAKAGAWA, H., Plant mutation breeding and biotechnology, Joint FAO/IAEA Programme, ISBN 97892-5-107022-2 (2012).
6. HUMAN, S., TRIKOESOEMANINGTYAS, SIHONO and SUNGKONO, Development of sorghum tolerant to Acid soil using induced mutation with gamma irradiation, Atom Indonesia Journal, 36 (1), ISSN 12261568 (2010).

7. HUMAN, S. and SIHONO, Sorghum breeding for improved drought tolerance using induced mutation with gamma irradiation, $J$. Agronomi Indonesia, 38 (2), ISSN 2085-2916 (2010).

8. NUR, A., HUMAN, S. dan TRIKOESOEMANINGTYAS,

Keragaman genetik gandum populasi mutan M3 di agroekosistem tropis, J. Ilmiah Aplikasi Isotop dan Radiasi, 10 (1), 35-44 (2014).

9. PURNAMANINGSIH, R., MARISKA, I., LESTARI， E.G., HUTAMI， S. dan YUNITA, S., Pengaruh iradiasi gamma dan Ethyl Methane Sulfonate terhadap pembentukan embriosomatik kedelai (Glysine max L.), J. Ilmiah Aplikasi Isotop dan Radiasi, 10 (1), 71-80 (2014).

10. BATAN. Deskripsi varietas unggul hasil pemuliaan mutasi: padi, kedelai, kacang hijau, sorgum, Pusat Diseminasi dan Kemitraan, BATAN, 38 (2016).

11. INDRAYANTI, R., MATTJIK, N.A., SETIAWAN, A., SUDARSONO. Radiosensitivitas pisang cv. Ampyang dan potensi penggunaan iradiasi gamma untuk induksi varian, J. Agronomi Indonesia, 39 (2), 112-118 (2011).

12. NASUTION, M.A., POERWANTO, R., SURACHMAN, $M$., TRIKOESUMANINGTYAS, Studi keragaman genetik nanas (Annanas 
Comunus L Merr) hasil persilangan berdasarkan penandaan RAPD, $J$. Agronomi Indonesia, 38 (2), ISSN 2085-2916 (2011).

13. BARTHOLOMEW, D.P., R.E. PAULL., dan K.G. ROHRBACH, The Pineapple Botany Production and Used, University of Hawaii at Manoa Honolulu USA (2002).

14. HUMAN, S., ANDREANI, S. SIHONO and W.M. INDRIATAMA, Stability test for sorghum mutant lines derived from induced mutations with gamma-ray irradiation, Atom Indonesia Journal, 37 (3), ISSN 12261568 (2011).
15. KODYM, A., AFZA, R., FOSTER, B.P., UKAI, Y., NAKAGAWA, H. dan MBA, C., Methodology for physical and chemical mutagenic treatments. Dalam SHU, Q.Y., FOSTER, B.P., NAKAGAWA, H., Plant mutation breeding and biotechnology, Joint FAO/IAEA Programme, ISBN 97892-5-107022-2 (2012).

16. RASYAD, A., MANURUNG, G.M.E dan VAN SANFORD, D.A., Genotype $\mathrm{x}$ environment interaction and stability of yield components among rice genotypes in Riau province, Indonesia, Sabrao, J. of Breeding and Genetics, 44 (1), 102-111 (2012). 
Jurnal Ilmiah Aplikasi Isotop dan Radiasi

A Scientific Journal for The Applications of Isotopes and Radiation

ISSN 1907-0322

Vol. 12 No. 1 Juni 2016 